\title{
Assessment and International Students - black African Social Work students
}

\author{
Angie Bartoli, University of Northampton
}

\section{Acknowledgement}

This paper originated as a student project from the Post Graduate Certificate in Enhancing the International Student Experience.

\section{Introduction from Dr Dave Burnapp (Course Leader)}

This article builds on previous research carried out by the author and colleagues at the University of Northampton with a particular reference to African social work students. It investigates these students' approaches to learning, and focuses on assessment strategies. These students report that they encounter an 'other world' of assessment processes which they are not familiar with. The article compares the students' performance in different forms of testing and offers suggestions for future practice.

\section{Abstract}

This evaluative study focuses on the perceptions of black African (international and home) students on an undergraduate social work programme. In particular this article will consider the more traditional assessment of examinations, where the students perceived that their grades were higher due to a familiarity with the assessment strategy. In contrast, they referred to the bewildering 'other world' of less familiar assessment processes which demanded a deeper level of critical thinking skills for example in assignments. This evaluation aims to consider whether the African students' perceptions that their academic grades fared better dependent on the assessment process is in fact a reality compared to other less familiar ones.

Keywords: Social Work Education; HE assessment; African students 


\section{Introduction}

This study focuses upon a Social Work degree programme in a post 1992 University within the East Midlands area. In particular this paper will focus on African social work students. The social work profession is currently regulated by the General Social Care Council (GSCC). The number of African students enrolled onto this Social Work programme is steadily increasing, mirroring the national trend within Higher Education (HE) (GSCC, 2009). The literature in respect of the black African social work student enrolled on programmes in England is scarce and this study will contribute towards this knowledge base.

During 2008, together with two other academic colleagues, I undertook a study with Black African social work students (Bartoli et al. 2008). The collective and anecdotal teaching experience was that this particular group of students' approach to learning was different to home students, gaining lower grades or failing aspects of their assessments. In many ways the African students' experience appeared to be more challenging, both for the learners, in terms of academic progression, and for educators endeavouring to support the students. The study at that time was based on a focus group discussion and questionnaires which led to a number of issues being identified by the students and summarised by the following themes: peer support group, a dedicated notice board within the Division, inclusive reading lists, practice learning experiences and assessment strategies.

This evaluation will focus on this last theme; assessment strategies. During the focus group discussions the students highlighted that some forms of assessment were more familiar to them than others. In particular, this included the more traditional assessment of time-limited closed book examinations, where the students perceived that their grades were higher due to knowing what was expected of them. In contrast, they referred to the bewildering 'other world' of less familiar assessment processes which demanded a deeper level of critical thinking skills and what Ryan (2005:99) refers to as "decoding" for example in assignments, presentations and reports. Developing and adopting critical thinking skills is challenging for all students, regardless of ethnicity (Carroll and Ryan 2005, Brown and Joughlin, 2007).

The significance of assessment cannot be over-emphasised in the context of Higher Education for both academics and students (Brown and Joughin, 2007). It is considered to be the measure of progress, success, and self esteem which culminates in the ultimate goal of graduation.

This study aims to consider whether the African students' perceptions that their academic grades fared better dependent on the assessment strategy is in fact a reality.

\section{Terms and Definitions}

The term international student within a HE context can be defined within a narrow and restrictive categorisation referring to the students' fee paying status. For the purposes of the previous (Bartoli et al. 2008) and current study, the definition of international student will extend to all Black African Social Work students who have received their formative education within their country of origin in the continent of Africa.

To consider international students as a homogenous group without recognising difference is unhelpful and furthermore it ignores diversity of experience, heritage, culture, language and history (Hyland et al. 2008, Trahr, 2007). It also dismisses different approaches to learning. For similar reasons in the aforementioned previous study (Bartoli et al. 2008) and this 
evaluation, it is not the intention to group all African students as the same. Any similarities commented upon are observations of one particular group of student rather than an attempt to be deterministic or compartmentalised. Furthermore, culture is not merely positioned within a geographical location; instead it permeates through and across cultures - none more so than in a continent as vast as Africa (Welikala and Watkins, 2008).

This particular group of African students, following the first focus group, set up a peer support group which they named Padare. This is a Zimbabwean term meaning meeting place. From this point on the group of students will be referred to as the Padare students, a self defining term.

Parallels can be drawn between the complexities of definitions about internationalisation within an educational context and discourses within social work in terms of profession identity (Cree, 2003) and what constitutes international social work (Gray and Fook 2004, Nagy and Falk 2000, Razack, 2009, Hugman 2010).

The definition of internationalisation within Higher Education has been the subject of much heated debate and academic discourse. The definition has a number of meanings, interpretations and applications (Koutsantoni, 2006) dependent on individual, political, national or organisational standpoints. This continues to evolve. Similarly, "social work is always subject to competing claims of definition and practice and cannot be separated from the society in which it is located" (Cree, 2003:4). As in the internationalisation of Higher Education, International Social Work can be seen as an approach based upon Western educational and social ideologies which are then imposed onto other countries without taking into account the issues relating to diversity and curricula relevance. Gray and Fook (2004: 627) argue that what is being 'touted as 'universal social work' is 'Western social work' in the same way that globalisation is equated with Westernisation or even Americanisation".

Comparisons can be made between the expansion of the meaning of internationalisation within Higher Education in terms of this going beyond the recruitment of students from overseas; and instead, focussing on broader issues relating to integrations of teaching, learning and research. Equally, the definition of International Social Work, is shifting to encompass more than the transportation of Western educational programmes. It extends to an internationalised curriculum within Universities in the UK that relates not just to the content but to issues pertinent to pedagogy and cross-cultural understanding (Brydon, 2010). The influence of imperialism within pedagogical perspectives and social work practice is evident (Gray and Fook, 2004).

\section{Literature Review}

The literature available on the academic achievement levels of international students is limited and with polarised conclusions. Morrison et al. (2005) cites studies which demonstrate that international students outperform other students and are less likely to drop out of their studies (for example, Pauley, 1988, Williams, 1989, Wright and Cochrane, 2000 cited in Morrison et al. 2005). In contrast, Morrison et al (2005) highlights research that indicates international students perform less well than home students ( for example, Makepeace and Baxter, 1990 cited in Morrison et al. 2005). It is debatable how helpful and appropriate such comparisons of studies are, given that they are undertaken in different countries, in differing institutions, within different disciplines and different students (Morrison et al.2005). 
More recently, the research has begun to address the complexities involved in academic achievement of international students and moved away from the simplicity of making comparisons (Morrison et al. 2005). De Vita's $(2002,2007)$ work in this area has sought reasons for such differences. Similar to the original Padare study (Bartoli et al,.2008), De Vita (2002) found that international students achieved lower marks in some forms of assessment than home students.

De Vita's study (2002) suggests that assessment through examination disadvantages international students, which contradicts the experience of the Padare students. De Vita's conclusions (2002) based on MBA Business Study students, is supported by Smith (2011) whose more recent work, also with MBA Business Study students concurs that students with English as a second language are disadvantaged through the assessment by examinations.

All practices, including assessment can be considered as "culturally determined" (Brown and Joughin, 2007:68). Furthermore, literature concerning "developing culturally inclusive assessment" (De Vita, 2007: 161) within HE remains limited and instead has focussed on international students' experiences and differing approaches to learning in different cultures (De Vita 2007, Jones and Brown 2007, Midgley 2001, Montgomery 2010). Brown and Joughin (2007) argue that all students need to learn about assessment strategies as well as subject content. Race (2010) further suggests that learners need to be trained as opposed to educated to 'play the game' of assessment related to familiarisation of expectations and being able to practice the art of assessment.

According to Race (2010:60), "assessment is broken in higher education". He attributes this view to four main factors: higher numbers of students, internationalisation, assessment driven learning, the constant strive to improve standards of assessment and finally the need to diversify assessment to everyone's advantage. Similarly, Struyven et al. (2002:1) propose that the expansion of assessment methods used within $\mathrm{HE}$ is a shift from a "test culture to an assessment culture."

The use of examinations within Higher Education has long been a traditional assessment strategy. Some have argued that examinations test what students can remember rather than what they know (Entwistle and Entwistle 1991, Scouller, 1998, Entwistle 1991). Research in learning in Higher Education has for some time theorised that there are two approaches to learning, usually referred to either as a deep or surface approach (Biggs 1987, Au and Entwistle 1999, Entwistle 1991). Scuoller (1998) goes on to argue that an approach to learning is underpinned by a strategy and motivation. Later studies as outlined by Struyven et al. (2002), introduced an additional approach to learning known as the strategic or achieving approach where the students' intention is to achieve the highest possible grades by adopting good time management skills according to the assessment strategy set by educators. These theories are combined and illustrated in the diagram below. 


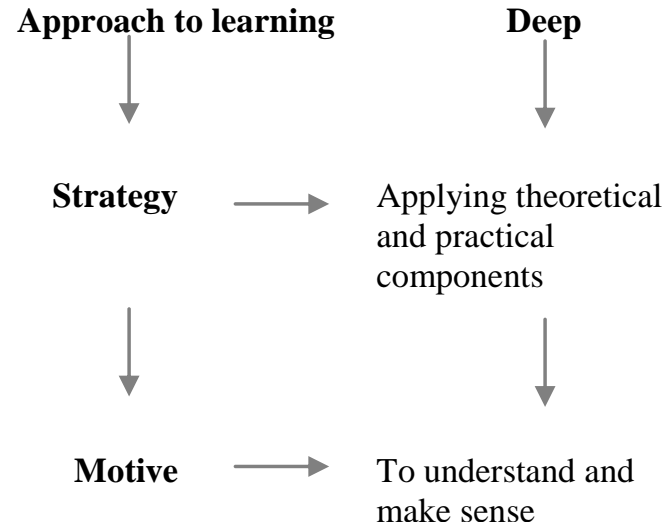

make sense

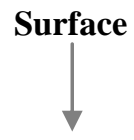

Discrete and specific information listed

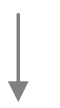

Reproduced in exam like conditions to pass course

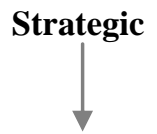

Utilise good time management and study skills

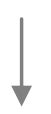

To achieve highest possible grades

Figure 1: Approaches to learning

As posited by Bartram and Bailey (2010) research on students' assessment preferences is limited. However, they suggest that the very nature of contemporary Higher Education where learners are typically balancing their studies with employment or other responsibilities such as child care, promotes strategic learners. As stated by Race (2010:65) "strategic learning is regarded as 'learning for the exam"" which is about making decisions about what to learn deeply, investing in aspects of learning and settling on a certain level of learning.

\section{Outline of study}

The Social Work Degree programme offers students a range of assessment strategies, which include:

- Assignments (ranging from 1000-3000 words)

- Group presentations

- Viva (individual oral presentation at level 4)

- Academic posters

- Reflective logs (diaries)

- Portfolios (relating to practice learning/placements)

- Examination (Law module- a closed book exam at level 4)

- Dissertation (10,000 words)

The viva and group presentations are assessed by a panel consisting typically of a mixture of academic staff, practitioners, practice assessors and service users. All assessment meets with the University regulations in terms of moderation, GSCC (professional regulatory body) requirements and scrutiny by external examiners.

For the purposes of this evaluation, existing University data has been used to examine whether the Padare students' (from four cohorts spanning 2006-10) perceptions that their academic grades faired better dependent on the assessment strategy is in fact a reality. In particular the hypothesis presented by the Padare group in the initial study (Bartoli et al. 2008) where it was suggested that they faired more favourably in examinations will be analysed. 
In addition to this, some quotes by the students from the original Padare study will be used to reflect the students' voice. These will be highlighted in italics.

The number of African students enrolled on social work programmes is increasing at this HEI, which reflects the national picture (GSCC, 2009).

The statistics relating to African students in the HEI where this evaluation was undertaken are:

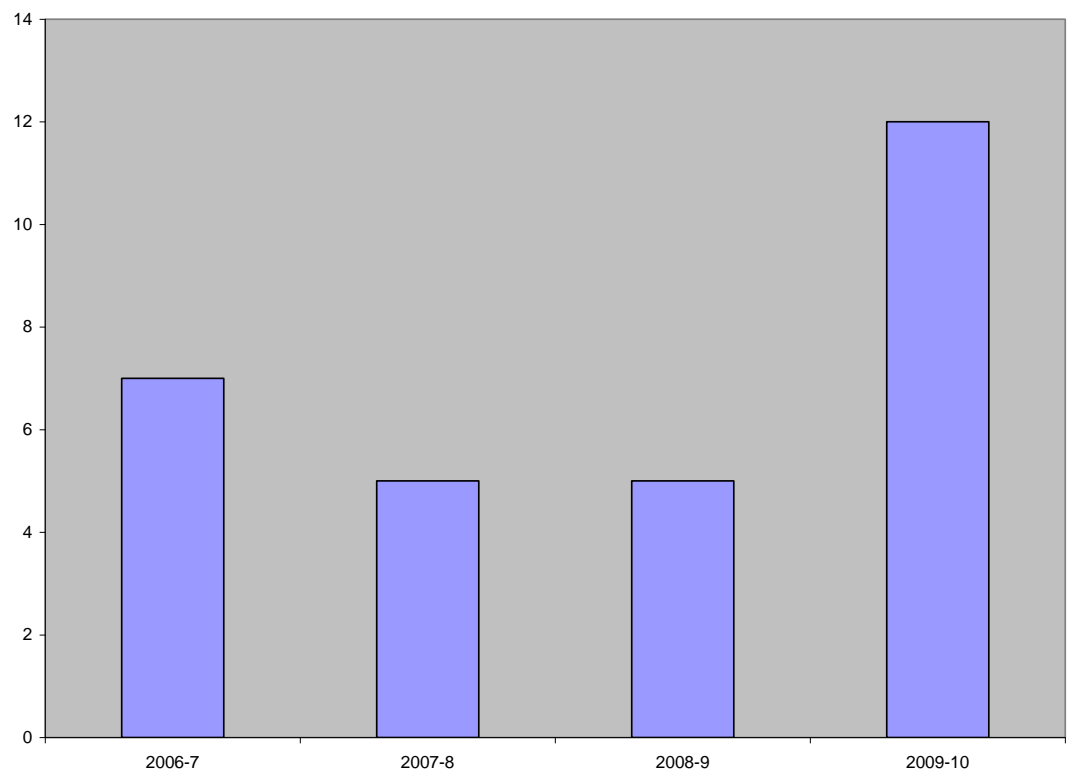

Figure 2: African student enrolment

\section{Research methodology}

Due to time constraints and access to data, it has only been possible to collate and analyse data within modules that have only one item of assessment. Consequently, three specific modules were considered and chosen because each has one item of assessment, contrasting nature of assessment and covering each level of study. They are as follows:

- Law module using a closed book examination (level 4)

- Gendering social work module using a workbook of evidence ( level 5)

- 10,000 word dissertation (level 6)

Two sets of the cohorts (2006-7 and 2007-8) have already graduated, the remaining two sets (2008-9 and 2009-10) are yet to graduate and therefore there is only limited data available.

In addition, each cohort was considered separately, and the data was analysed in terms of the Padare students' overall highest and lowest grade for all cohorts at each level of study.

\section{Findings}

The Law examination is taken by students in their first year (level 4) of study. It is a 2 hour, closed book examination, set at the end of the second term directly after the 12 week module has been taught. The teaching comprises a mixture of lecturers given by the module leader (an expert in child care law), visiting lecturers with specialised knowledge, group work, all supported by e-learning materials published by Social Care Institute for Excellence (1) 
The law examination is divided into two parts. Part A is compulsory and comprises 30 questions based on differing aspects of legislation including: general legal concepts, child care, human and children's rights, youth justice, domestic violence, mental health, National Health Service and Community Care and discrimination. Part B is based around two case studies, one centred on child care and the other on adult mental health issues. Students are required to select one case study and answer 25 multiple choice questions based on their chosen study.

The design of the law examination includes the two most popular formats of questions, the multiple choice often classified as an objective structured selection type and secondly the subjective question asking for essay or short answers. (Zeidner, 2001)

Generally in the law examination all of the social work students achieve a high grade and since 2007 the average student grade for this assessment is A minus compared to C plus in previous years. This has been commented upon by external examiners and within the Annual Course Review (University of Northampton, 2010). The law examination grades of 29 Padare students were collated spanning 4 cohorts. One student transferred to the social work programme from another University and therefore was not required to take the examination this is noted as APEL (Accredited Prior Education and Learning). The grades of the Padare students span four grading bands as follows:

- Grade A: $36 \%$

- Grade B: $32 \%$

- Grade C: $21 \%$

- Grade D: $11 \%$

Since 2006, only 3 students have failed the law examination and this has not included a Padare student. Over a third of Padare students to date have achieved a grade within the A band. Furthermore, the Padare students' law examination grades have improved year upon year, with the exception of cohort 2008-9, and in the most recent examination have reached the same average pass rate as the rest of the cohort.

\begin{tabular}{|l|l|l|l|l|}
\hline Cohort & $2006-7$ & $2007-8$ & $2008-9$ & $2009-10$ \\
\hline Average Grade Padare Students & C Plus & B & B Minus & A minus \\
\hline Average Grade all students & C Plus & A minus & A minus & A minus \\
\hline
\end{tabular}

Figure 3: Comparative law examination grades

These results together with the data evidencing that the majority of the 29 Padare students' best grade for their first year of study (level 4) is the law examination, would suggest that the Padare student's belief that they fair better in examinations is supported. However, it must be noted that this is the only examination in the entire three year programme. Interestingly, it is also the highest grade achieved by all of the social work students.

In addition to this the assessment outcomes of each Padare group cohort has been examined to consider which module the Padare students achieved their highest and lowest grade. As mentioned previously, the entire assessment data is only available for two cohorts: 2006-7 and 2007-8. 
At level 4 (first year of study) of the 29 Padare students, 14 of the students' highest grade was for their Law examination as already mentioned.

At level 5 (second year of study) the Gendering Social Work module is assessed by a workbook of evidence. Two cohorts (2006-7 and 2007-8) have completed this module, comprising of 17 Padare students. For three (3) of these students, this was the module in which they achieved their highest grade.

At level 6 (third and final year of study) of the 12 Padare students, their Dissertation Module $(10,000$ word) was for $50 \%$ (6) their highest and for $50 \%$ (6) their lowest grade. However, it must be noted that for the purposes of this study, the practice grades have been removed, and for many students this was in fact their highest grade at level 6.

In the academic year 2009-10, apart from law, the average module grade for the whole social work programme for all students is $\mathrm{C}$ minus. For the Padare students, the average module grade is D, with the exception of Law, which is now A minus.

\section{Discussion}

The original Padare study (Bartoli et al. 2008) and this current study indicate that African students studying the Social Work programme perform and academically achieve differently. Their formative knowledge of social work practice which is acquired through community based work within their countries of origin or the care work that they engage in prior to commencing their studies is a world apart from the realities of the complexities and bureaucracy surrounding contemporary UK social work practice in the UK. (McGregor 2007, Bartoli et al. 2008). Social work can be seen as having its own distinct culture defined by contextual history, political landscape, traditions and norms (Tunney, 2002).

Within the previous study, a number of the Padare students talked of their desire to achieve a degree qualification from a UK university and to return to their country of origin to practise in the future. A number of the students were awaiting political stability and security. However, given the arguments about the appropriateness and relevance of social work education content which is steeped in westernised ideology, this brings into question the applicability of their learning within an African context.

Many of the Padare students begin their social work education with a degree or professional qualification acquired in their home country. This includes teaching qualifications, business management and architectural studies. This would support De Vita (2007) claim that assessment practices are culturally determined and that marking and assessment cultures differ from nation to nation.

In a study undertaken by Hyland et al. (2008) a number of academic challenges faced by the international learners were identified. These include essay writing, time management, proof reading, critical analysis and avoiding plagiarism. The sitting of an exam is not highlighted as a challenge, yet assignment writing is.

The design of the Law examination is such, that unlike other assessment strategies (for example assignments) the answers are not dependent on coherent sentence construction or logical arguments. Therefore it could be argued that some of the potential language barriers for the Padare students are removed by the exam which demands one word or short sentence 
answers. As Cammish (1997:143) suggests, "the likelihood of mistakes in sentence construction seems to increase in proportion to sentence length".

The Padare students talked of the 'other world' of assessment when referring to assignment writing. In particular they were confused and 'struggling to know what is expected in assignments' and attributed this to being more familiar with closed book examinations. Ryan (2005:99) suggests that assessment tasks, and in particular assignments "contain hidden codes or 'prompts' only apparent to students familiar with the academic discourse". This would support earlier findings within the literature that the art of assessment as well as the subject content needs to be taught (Brown and Jouglin 2007, Race 2010).

During the original Padare study and the literature on international students, the challenges associated with being able to think and write critically is highlighted (Brown and Joughlin, 2007). However, this is not peculiar to international students and it has also been recognised that home students often grapple with assessment requirements (Carroll and Ryan 2005, Brown and Joughlin, 2007). Critics of examinations argue that this form of assessment promotes surface learning, which might suit students unfamiliar or less effective in critical writing (Entwistle and Entwistle 1991, Struyven et al. 2002, Clarke et al. 2005).

It could be suggested that the social work students approach to learning of legal frameworks is only at surface level, where the students learn for the exam and it is their memory rather than knowledge that is tested. Knowledge and application of the law is an intrinsic part of good social work practice and therefore the students' understanding and application of legislation is assessed in different aspects of the programme including during 200 days practice learning.

Conversely, Race (2010) states that examinations based on problem solving and case studies are "much better at not rewarding reproductive learning". He further argues that multiple choice questions do actually test learner's decision making process, which is a key social work skill. The Law examination in question is both a mixture of problem solving and multiple choice questions.

Plagiarism is a significantly controversial topic within Higher Education (Ryan 2005, Jones and Brown 2007), with allegations often made that international students are the "worst culprits" (Brown and Joughlin 2007:67). An advantage of examinations as an assessment tool is that authenticity is not an issue for either the educator or learner.

Much of what is known about international students' academic achievements is through comparative studies which highlight more differences than similarities and rarely take into account prior learning and experience (De Vita 2007).

Within the literature international students are often characterised through a "deficit model" (De Vita 2007:1) as rote learners, plagiarists, unable to critically think or write and demanding of educators time (McNamara and Harris 1997, Jones and Brown 2007). However, as suggested by Carroll and Appleton (2007:78) the support offered to international students needs to be "front-ended" in order to address the system rather than it becoming further personalised or labelling. 


\section{Research reflections and conclusion}

This study concludes that as hypothesised by the Padare students themselves, the assessment task where they fair best (in terms of achieving highest grades) is the law examination. However, it is acknowledged that there is only one examination throughout the social work three year degree programme. It is also noted that it is not just the Padare students that achieve high grades within the Law examination, and that the average grade for this assessment for the whole cohort is A minus compared to $\mathrm{C}$ minus for other modules.

The Padare students profess that the reason they achieve higher grades within the examination is because it is an assessment strategy that they are familiar with. It could also be suggested, that for students who have language difficulties, the design of the exam is such that this does not hinder the students' achievement.

Given the high academic achievement of this examination, it could be implied that it is too easy or not rigorous enough. Yet it meets all academic and professional body requirements and is externally moderated. Maybe the students should be commended for their achievements rather than their results viewed as suspicious. The assessment strategy is 'fit for purpose' in that it is a reasonable way in which to test a knowledge based subject. As Brown and Joughin (2007) state, when assessment tasks are 'fit for purpose' with international students in mind, home students often benefit, therefore there are advantages for all students.

Critics of examinations claim that this form of assessment encourages a surface and strategic level approach to learning (Scouller 1998, Biggs, 1987, Enstwistle and Entwistle 1991) and furthermore this is promoted by the very nature of contemporary Higher Education where students typically juggle studies, home commitments and employment. An added factor to this is that the Padare students often support family members in their home countries both financially and emotionally, adding an additional responsibility (Bartoli et al. 2008).

However, it is possible to pose questions within examination conditions that require cognitive and analytical thinking skills, and so it is incumbent on the educators to ensure questions are posed that test knowledge as well as memory (Au and Entwistle 1999, Clarke 2005). Au and Entwistle (1999) in their research with Chinese students' approach to learning and assessment argue that the ability to remember knowledge is akin to demonstrating understanding and that "memorisation and understanding seem to have become part of a single process of learning, at least when preparing for examinations" (p.11).

Race (2010) states that assessment processes should be diversified so that no student is repeatedly disadvantaged. Conversely, Brown and Joughin (2007) suggest that using too many different assessment methods disadvantages students as they need time and practice to get used to assessment requirements. Educators are tasked with the responsibility of promoting fairness, which might demand that the approach to teaching is different (Carroll and Appleton, 2007).

As highlighted in the literature review, research surrounding students' preferences of assessment strategies and culturally inclusive assessment is scarce. In one study (Struyven et al. 2002) it was found that within conventional assessment like examinations, multiple choice formats are favoured over essay type questions. Yet, when conventional (for example examinations) and alternative assessment (for example group presentations) were compared, 
students perceived the alternative assessment as being fairer. The Padare students did not share this view.

The findings of this study conclude that the perceptions of the Padare students are borne out and validated by the data - they fare better in the examination compared to other assessment tools. This outcome contradicts the research to date, which states that examinations disadvantage international students and those with English as a second language (De Vita 2007, Smith 2011, Bailey undated). Given the scarcity of literature within this field of study and the polarised outcomes, more research is needed to better inform educators and learners.

\section{References}

Au, C. and Entwistle, N. (1999) 'Memorisation with understanding' in approaches to studying: cultural variant or response to assessment demands? Paper presented at the European Association for Research on Learning and instruction Conference (Gothenburg, August 1999) Available at: http://www.leeds.ac.uk/educol/documents/00001728.htm [Accessed on 17.12.2010]

Bartoli, A., Kennedy, S. and Tedam, P. (2008) Practice learning: Who is failing to adjust? Black African student experience of practice learning in a social work setting, The Journal of Practice Teaching in Health and Social Care. 8 (2) pp75-90

Bartram, B. and Bailey, C. (2010) Assessment preferences: a comparison of UK/international students at an English university. Research in Post-Compulsory Education 14 (2) pp 177-187

Bailey, C. (undated) Comparing the experience of Chinese and West African students at a British university: findings from a survey. Available from:

http://wlv.openrepository.com/wlv/bitstream/2436/83340/1/Solent_06_Carol_Bailey.pdf [Accessed on 07.01.2011]

Biggs, J.B. (1987) Student Approaches to Learning and Studying. Melbourne: Australian Council for Educational Research Available at: http://eric.ed.gov/PDFS/ED308201.pdf [Accessed on 21.12.2010]

Brown, S. and Joughin, G. (2007) Assessment and international students: helping clarify puzzling processes. In: Jones, E. and Brown, S. (eds) (2007) Internationalising Higher Education. Oxon: Routledge. pp. 57-71

Brydon, K. (2010) Have You Had Your Lunch Yet? A Case Study on Teaching International Social Work Students. Social Work Education, First published on: 31 August 2010 (iFirst) 110

Cammish, N.K. (1997) Through a glass darkly: problems of studying at advanced level through the medium of English. In: McNamara, D. and Harris R. (eds) (1997) Overseas students in higher education: Issues in teaching and learning. Oxon: Routledge. pp 143-155

Carroll, J. and Ryan, J. (2005) (eds) Teaching International Students: Improving Learning for All Oxon: Routledge 
Carroll, J. and Appleton, J. (2007) Support and guidance for learning from an international perspective. In: Jones, E. and Brown, S. (eds) (2007) Internationalising Higher Education. Oxon: Routledge. pp 72-85

Clark, P.D., Heaney, J-G., Gatfield, T. J. (2005) Multiple Choice Testing: A Preferred Assessment Procedure That is Fair to All Our Business Students Anzamc 2005 Conference: Marketing Education pp 51- 57

Cree, V. E. (2003) (ed) Becoming a Social Worker. Oxon: Routledge

De Vita, G. (2002) Cultural equivalence in the assessment of home and internal business management students: a UK exploratory study, Studies in Higher Education, 27, 221-231

De Vita, G. (2007) Taking stock: an appraisal of the literature on internationalizing HE learning. In: Jones, E. and Brown, S. (eds) (2007) Internationalising Higher Education. Oxon: Routledge. pp. 154-168

Entwistle, N. (1991) Approaches to learning and perceptions of the learning environment: Introduction to the Special Issue Higher Education 22 pp 201-204

Entwistle, C. A. and Entwistle, N. (1991) 'Memoraisation with understanding' in approaches to studying: cultural variant or response to assessment demands? Paper presented at the European Association for Research on Learning ad Instruction Conference, August 1999) Available: www.leeds.ac.uk/educol/documents/00001728.htm [Accessed on 17th December 2010.

Gray, M. and Fook, J. (2004) The quest for a universal social work: some issues and implications. Social Work Education. 23 (5), 625-644

Hugman, R. (2010) Understanding International Social Work: A Critical Analysis. Basingstoke: Palgrave MacMillan General Social Care Council (2009) Raising Standards in Social Work Education in England 2007-8. London: GSCC

Hyland, F., Trahar, S., Anderson, J. and Dickens, A. (2008) A Changing World: the internationalisation experiences of staff and students (home and international) in UK Higher Education. Higher Education Academy: Bristol

Jones, E. and Brown, S. (eds) (2007) Internationalising Higher Education. Oxon: Routledge

Koutsantoni, D. (2006) Paper 1: Definitions: What is Internationalisation? In: Leadership Summit 2006: The Leadership and Development Challenges of Globalisation and Internationalisation. London: Leadership Foundation for Higher Education. pp. 10-12

McGregor, J. (2007) Joining the BBC (British Bottom Cleaners): Zimbabwean Migrants and the UK Care Industry. Journal of Ethic and migration Students 33 (5) 801-824

McNamara, D. and Harris, R. (eds) (1997) Overseas Students in Higher Education: Issues in teaching and learning. London: Routledge

Midgley, J. (2001) Issues in International Social Work, Journal of Social Work 1 (1) 21-35 
Montgomery, C. (2010) Understanding the International Student Experience. Basingstoke: Palgrave MacMillan

Morrison, J., Merrick, B., Higgs, S., and Le Métais, J. (2005) Researching the performance of international students in the UK, Studies in Higher Education, 30: 3, 327-337

Nagy, G. and Faulk, S. (2000) Dilemmas in international and cross-cultural social work education. International Social Work 43 (1) pp.49-60

Race, P. (2010) Making Learning Happen: A Guide for Post-Compulsory Education. London: Sage

Razack, N. (2009) Decolonizing the pedagogy and practice of international social work. International Social Work 52 (9) 9-21

Ryan, J. (2005) Improving teaching and learning practices. In Carroll, J. and Ryan, J. (eds) (2005) Teaching International Students: Improving Learning for All Oxon: Routledge

Social Care Institute for Excellence (available at:

http://www.scie.org.uk/publications/elearning/law/law02/index.asp) [Accessed 08.01.2011]

Scouller. K. (1998) The influence of assessment method on students' learning approaches: Multiple choice question examination versus assignment essay. Higher Education 35 453472

Smith, C. (2011) Examinations and the ESL student - more evidence of particular disadvantages Assessment and Evaluation in Higher Education, 36, 1, pp. 13-25

Struyven, K., Douchy, F. and Janssens, S. (2002) Students perceptions about assessment in higher education: a review. Education-Line. Available on http://www.leeds.ac.uk/educol/documents/00002255.htm [Accessed 16th December 2010].

Tunney, K. (2002) Learning to teach abroad: Reflections on the role of the visiting social work educator. International Social Work 45 (4) pp 435-446

Trahr, S. (2007) Teaching and learning: the international higher education landscape.' Bristol: The Higher Education Academy, March.

University of Northampton 2010 Annual Course Review: Social Work

Welikala, T. and Watkins, C. (2008) Improving Intercultural Learning Experiences in Higher Education: Responding to cultural scripts for learning. London: Institute of Education, University of London

Zeidner, M. (2001) Essay Versus Multiple-Choice Type Classroom Exams: The Student's Perspective Journal of Educational Research 80 (6) pp 352-358 


\section{About the author}

Angie Bartoli is Senior Lecturer in Social Work in the School of Health at the University of Northampton.

Email: angie.bartoli@northampton.ac.uk 